Cell Research (2003); 13(1):49-58

http://www.cell-research.com

\title{
Clusterin mRNA expression in apoptotic and activated rat thymocytes
}

\author{
Jung-Hyun PARK ${ }^{1}$, Jee-Sun PARK ${ }^{2}$, Sung-Kyu JU², Kwan-Bok LEE ${ }^{2}$, Yoo-Kyoung PARK ${ }^{3}$, Myung-Hee \\ $\mathrm{KANG}^{3}$, Shin-Young NA ${ }^{4}$, Kwan-HeE YOU ${ }^{2}$ * \\ ${ }^{1}$ Experimental Immunology Branch, National Cancer Institute, NIH, Bethesda, MD 20892, USA \\ ${ }^{2}$ Department of Biology, College of Natural Science, Chungnam National University, 220 Gung-dong, Yuseong-gu, \\ Daejeon 305-764, Korea \\ ${ }^{3}$ Department of Food and Nutrition, Hannam University, Daejeon 306-791, Korea \\ ${ }^{4}$ Institute for Virology and Immunobiology, University of Wuerzburg, Versbacher Str. 7, 97078 Wuerzburg, \\ Germany
}

\begin{abstract}
Clusterin is a $75-80 \mathrm{kDa}$ heterodimeric glycoprotein, that is produced in most tissues but which exact biological role is still not clear. Particularly, its role in protection or promotion of apoptosis is heavily disputed, since data supporting both views have been reported in several independent studies. To clarify this issue, and also to determine whether clusterin expression itself might be affected by apoptosis, in the present study, rat thymocytes were treated with dexamethasone, -a synthetic glucocorticoid that elicits apoptosis in thymocytes-, and clusterin mRNA expression was analyzed by semi-quantitative RT-PCR before and after induction of apoptosis. Interestingly, neither the treatment with dexamethasone in vitro nor triggering of apoptosis in vivo up- regulated clusterin expression, opposing the view that clusterin is involved in apoptotic processes. On the other hand, a new clusterin mRNA isoform was detected and isolated, whose expression was restricted to freshly isolated thymocytes. This novel isoform lacks the post-translational proteolytic cleavage site and is therefore predicted to encode a monomeric protein. The biological function under normal circumstances, however, will need further investigations for clarification. While apoptosis could not modulate clusterin expression, activation of thymocytes with concanavalin A and interleukin-2 resulted in up-regulation of clusterin mRNA level, indicating that clusterin expression is rather under the control of cell activation-mediated rather than apoptosis- induced signals.
\end{abstract}

Key words: clusterin, sgp-2, thymocytes, apoptosis, mRNA isoforms.

\section{INTRODUCTION}

Originally discovered in ram rete testis fluid upon its ability to mediate aggregation or clustering of various cells in vitro[1],[2], clusterin has been since then found in virtually all tissues throughout the body [3]. While its biological role is still under dispute, a variety of putative functions have been suggested. These include a role in serving as a lipid transport

* Corresponding author: Prof. Kwan-Hee YOU, Tel: 0082-42-8215498; Fax: 0082-42-822-9690 E-mail: khyou@cnu.ac.kr Received Aug-30-2002 Revised Jan-6-2003 Accepted Jan-9-2003 molecule[4], a regulator of complement-mediated cytolysis[5] as well as a playing role in the protection of the cell membrane from stress by acting as a secreted heat shock protein[6] or involvement in the cellular response upon apoptosis[7]. Such variant functional roles have lead to reporting the same protein under several different names, which include sulfated glycoprotein-2 (sgp-2)[8], ionizing radiationinduced protein-8 (XIP8), testosterone-repressed prostate message-2 (TRPM-2) as well as clusterin and Apo/J. While there is now a general agreement on referring this protein as clusterin[9], a consen- 
sus on its biological function has still not been reached. Current reports try to explain those different functional aspects of clusterin by postulating this protein as a novel secreted chaperone[9], however, further supporting results are required to reach a definitive conclusion.

In the case of its involvement in apoptosis, clusterin plays a heavily disputed role. Since the first description of clusterin mRNA induction in apoptotic rat prostate cells[10], clusterin expression has been repeatedly confirmed in connection with apoptosis. Rat thymocytes[11] and mouse neuronal cells[12] were shown to accumulate clusterin mRNA upon induction of apoptosis. Also tumor cells were identified as source of increased clusterin expression, which was considered as a result of the apoptotic processes[13]. In contrast, other groups have reported a lack of evidence for clusterin expression in apoptotic thymocytes[14],[15] while others have shown that, not apoptotic cells themselves but rather, bystander cells surviving the apoptotic process might be the source of clusterin production[16][16]. In addition to these reports, contradictory observations on the role of clusterin in both protecting[17] and promoting apoptosis[18] have been reported; therefore the biological function of clusterin during apoptosis is indeed confusing and conflicting.

The present study was performed to clarify some aspects of this issue, first by analysis of clusterin mRNA expression upon induction of apoptosis both in isolated rat thymocytes in vitro, and by further analysis in vivo. In contrast to previous studies using Northern blot analysis, in this study clusterin mRNA was quantified and analyzed by reverse transcription (RT)-PCR and competitive RT-PCR, which represent more sensitive tools for mRNA analysis. The apoptotic status of rat thymocytes was monitored on both molecular and cellular level using DNA fragmentation assays and cell surface molecule analysis, respectively.

\section{MATERIALS AND METHODS}

\section{Thymocyte isolation and induction of apoptosis}

Sprague-Dawley rats of both sexes (6-8 weeks) were killed by $\mathrm{CO}_{2}$ asphyxiation, and their thymi were isolated for further processing into single cell suspension. In brief, thymi were passed through a 40-mesh stainless sieve (Sigma, St. Louis, MO, USA) into ice-cold Hank's balanced salt solution (HBSS), and single cell suspensions of isolated thymocytes were prepared in RPMI-1640 media (Life Technologies Inc., Grand Island, NY, USA) supplemented with $10 \%$ fetal bovine serum (Life Technologies Inc.), 2 $\mu \mathrm{M}$ glutamine, penicillin $(100 \mathrm{U} / \mathrm{ml})$, streptomycin $(100 \mu \mathrm{g} / \mathrm{ml})$ and $20 \mathrm{mM} \beta$-mercaptoethanol. Cells were maintained in a humidified $5.6 \% \mathrm{CO}_{2}$ atmosphere at $37^{\circ} \mathrm{C}$. Induction of apoptosis in thymocytes in vitro was performed by pulsing the cells with $1 \mathrm{mM}$ water-soluble dexamethasone (Sigma) for the indicated time values.

\section{Total RNA and genomic DNA isolation from normal and apoptotic thymocytes}

Isolation of total RNA was performed by the guanidium isothiocyanate method as originally described by Chomzynski and Sacchi[19]. In brief, $1 \times 10^{7}$ cells of thymocytes or $100 \mathrm{mg}$ thymi tissue fragments were first resuspended in $500 \mu \mathrm{l}$ of a guanidium isothiocyanate solution. After phenol/chloroform extraction, 400 $\mu \mathrm{l}$ of the upper aquatic phase was transferred into a new tube, and RNA was precipitated with 2.5 vol. absolute EtOH. The purity and intactness of the isolated RNA were determined by spectrophotometry and denaturing formaldehyde agarose gel electrophoresis, respectively. If necessary, isolated total RNA was treated with 2 units of RNase-free DNase I (RQ1 DNase; Promega, Madison, WI, USA) for $2 \mathrm{~h}$ at $37{ }^{\circ} \mathrm{C}$ to remove all possible genomic DNA contamination. Reverse transcription into cDNA was performed with the SuperScript II+ reverse transcriptase (Life Technologies Inc.) following the manufacturer's instructions. PCR was performed using the following primers for detection of clusterin and a-actin signals, respectively. Clusterin-up: 5'cgggcgtctggcatcata-3'; Clusterin-down: 5'-catgcggcttttcctgcg-3'; $\beta$ actin up: 5'-ccttcaacaccceagcca-3'; $\beta$ - actin-down: 5'ccaccagacagcactgtg-3'. Using reverse-transcribed cDNA, all PCR were performed after the following protocol: 2 min denaturation at $96^{\circ} \mathrm{C}$, then 36 cycles of a $45 \mathrm{sec}$ denaturation step at $95 \mathrm{oC}, 1 \mathrm{~min}$ annealing at $55{ }^{\circ} \mathrm{C}, 1 \mathrm{~min}$ elongation at $72^{\circ} \mathrm{C}$, and a final elongation step for $5 \mathrm{~min}$ at $72^{\circ} \mathrm{C}$. PCR was performed on a GeneAmp 2400 thermal cycler (Perkin Elmer, Foster City, CA, USA) using 1 unit of Taq polymerase (Promega) per reaction. The PCR products were analyzed in a 1.5\% TAE-buffered agarose gel. Analysis of DNA fragmentation by apoptosis was performed after the protocol as described by Homburg et al[20]. Briefly, for a single assay $1 \times 106$ cells were harvested and resuspended in cell lysis buffer $(0$. $5 \%$ SDS, $10 \mathrm{mM}$ EDTA, $50 \mathrm{mM}$ Tris-HCl, pH 8.0) and treated with proteinase $\mathrm{K}(0.5 \mathrm{mg} / \mathrm{ml})$ at $56^{\circ} \mathrm{C}$ for $2 \mathrm{~h}$. After an additional RNase digestion step with $0.25 \mathrm{mg} / \mathrm{ml}$ RNase A (Roche Molecular Biochemicals, Mannheim, Germany) at $37 \mathrm{oC}$ for $1 \mathrm{~h}$, an aliquot of the whole cell lysate was loaded in the well of a $2 \%$ TAE-agarose gel and analyzed by gel electrophoresis.

Cloning and characterization of the clusterin mRNA isoform

The two isoforms of the clusterin mRNA as amplified by RTPCR and Pfu DNA polymerase (Stratagene, La Jolla, CA, USA) with the primer pair "lusterin-up" and "lusterin-down" were 
isolated and subcloned for further characterization and nucleotide sequencing. The PCR products were eluted from a 1.8\% TAE-buffered agarose gel using the QIAquick gel extraction kit (Qiagen, Hilden, Germany) and subcloned into the pCR-Blunt IITOPO vector (Invitrogen, De Schelp, The Netherlands). Nucleotide sequencing was performed at the Genome Research Center of the Korea Research Inst. of Bioscience and Biotechnology, Taejon, Korea, using an ABI PRISM DNA sequencing kit and ABI PRISM 377 DNA sequencer (Perkin Elmer).

\section{Western blot analysis}

For determination of clusterin expression at protein level, Western blot analysis was performed. Freshly isolated thymocytes $\left(5 \times 10^{6} / \mathrm{ml}\right)$ were treated with concanavalin A $(4 \mu \mathrm{g} / \mathrm{ml})$ and IL-2 $(4$ $\mu \mathrm{g} / \mathrm{ml})$ or dexamethasone $(1 \mu \mathrm{M})$. After 6 hours, cells $\left(5 \times 10^{7}\right)$ were harvested and washed 3 times in ice-cold PBS. The cell pellet was resuspended in $375 \mathrm{ml}$ RIPA buffer $(150 \mathrm{mM} \mathrm{NaCl}, 1 \%$ Nonidet P$40,0.5 \%$ sodium deoxycholate, $0.1 \% \mathrm{SDS}, 50 \mathrm{mM}$ Tris- $\mathrm{HCl}, \mathrm{pH} 8$. 0 ) and incubated for $30 \mathrm{~min}$ on ice. Cell lysates were clarified by centrifugation at $13,000 \mathrm{~g}$ for $20 \mathrm{~min}$ and supernatants were collected for electrophoresis. Samples were boiled for $5 \mathrm{~min}$, and then same amounts of total protein were subjected to SDS-polyacrylamide gel electrophoresis. Proteins were transferred to Hybond-PVDF membranes in Tris-glycine buffer ( $48 \mathrm{mM}$ Tris$\mathrm{HCl}, \mathrm{pH}$ 8.3, $39 \mathrm{mM}$ glycine, 20\% methanol) using a semi-dry transfer unit (AP-Biotech, Sweden), and membranes were then blocked overnight at $4{ }^{\circ} \mathrm{C}$ with $5 \%$ nonfat dry milk in TBS-T (10 $\mathrm{mM}$ Tris-HCl, $\mathrm{pH} 7.4,150 \mathrm{mM} \mathrm{NaCl}, 0.05 \%$ Tween-20). Next day, rabbit anti-clusterin antiserum was applied to the blots to a 1 : 1000 dilution in TBS supplemented with $1 \%$ BSA. In a control blot, rabbit anti-actin polyclonal antibodies (Sigma) were applied to a concentration of $1 \mu \mathrm{g} / \mathrm{ml}$. Membranes were reacted with each primary antibodies for $1 \mathrm{~h} 30 \mathrm{~min}$ at room temperature with agitation. After 6 times washing with TBS-T, the membranes were probed with horse radish peroxidase-conjugated goat antirabbit IgG antibody (Sigma) diluted 1:5,000 in TBS for $1 \mathrm{~h}$ at room temperature. After 6 times washing with TBS-T, proteins were visualized by reaction with chemiluminescence detection reagents (AP-Biotech).

\section{In vivo administration of dexamethasone}

Induction of apoptosis in immature thymocytes was achieved by a single intra-peritoneal injection of $1.5 \mathrm{mg} / 300 \mathrm{~g}$ bodyweight water-soluble dexamethasone (Sigma) in to young adult SD rats as has been described by Sun et al[21]. After $24 \mathrm{~h}$, rats were sacrificed by $\mathrm{CO}_{2}$ asphyxiation and their thymi were isolated for further analysis.

\section{Fluorescence-activated Flow cytometry}

For cell surface analysis of normal and apoptotic rat thymocytes, single cell suspensions of rat thymocytes were prepared by grinding the respective thymi through a 40-mesh stainless sieve (Sigma). Cells were then washed once in cold HBSS, and the concentration of the cell suspension was adjusted to $1 \times 10^{6} / \mathrm{ml}$ in staining buffer
(0.1\% BSA, $0.02 \%$ Na-azide in PBS). Cell surface staining was performed by incubating each $3 \times 10^{5}$ cells in staining buffer with the corresponding antibodies for $30 \mathrm{~min}$ on ice. FITC-conjugated anti-rat CD4 antibody and phycoerythrin-conjugated anti-rat CD8 antibodies were purchased from Pharmingen (La Jolla, CA, USA). Data acquisition was performed using the FACScalibur (Becton Dickinson, Mountain View, CA, USA) flow cytometer, and data were analyzed using the CellQuest software program (Becton Dickinson).

\section{Semi-quantitative RT-PCR of clusterin $m R N A$ expression}

The semi-quantification of clusterin mRNA was performed by primer competition for which serially diluted internal control plasmids were co-amplified in a series of PCR either for the detection of cytoplasmic b-actin or clusterin mRNA. After the reaction, PCR products were resolved in a 1.8\% TAE-buffered agarose gel, and the signal intensity of each band was quantified by densitometric analysis of the EtBr-stained DNA using a CCD-camera linked image analyzer system (Vilbert Lourmat, Marne La Valee, Cedex, France). The plasmid numbers used as internal standards were calculated using the following equation that has been described previously[22]: molecule number $=$ amount of internal standard (g) X Avogadro's number (molecules/mol)/mass of internal standard $(\mathrm{g} / \mathrm{mol})$. Using this equation, it was calculated that $1 \mathrm{mg}$ of $1000 \mathrm{bp}$ DNA would correspond to $1.52 \mathrm{pmol}$, which in turn would correspond to $9.1 \times 10^{11}$ molecules. In practice, the number of particular molecules, which are present in the reversetranscribed mRNA was estimated by the number of control plasmid copies which was required to reach the equivalence point in the PCR reaction, where the signal intensity of the competitor/ target ratio was 1 . The internal standards for performing semiquantitative PCR were constructed after the scheme as shown in Fig. 4. In brief, a partial b-actin cDNA fragment (529 bp) was amplified by RT-PCR using the primer pairs " $\beta$-actin up" and " $\beta$-actin down" The PCR product was then treated with the restriction enzyme EaeI, which resulted in the deletion of a $138 \mathrm{bp}$ fragment within the PCR product. The enzyme reaction was then directly used as template for a further PCR reaction, whereby the same " $\beta$-actin up" and " $\beta$-actin down" primers were employed for amplification. This time, two PCR products with different sizes were generated of which the smaller fragment was cloned into the pCR-Blunt II-TOPO vector (Invitrogen). The resulting plasmid was termed "pCR-rActin" and when using this plasmid as internal control for primer competition, an exactly $138 \mathrm{bp}$ smaller PCR product than the original cDNA-derived band is produced. The construction of the internal control for clusterin mRNA quantification was performed in a similar manner, whereby the 798 bp clusterin PCR fragment as amplified using the primer pair, "Clusterin-up" and "Clusterin-down" was digested with the endonuclease NcoI to generate a 148 bp deletion fragment. The restriction enzyme reaction was then used as template for another round of PCR, whereby the shorter PCR product was cloned into the pCR-Blunt II-TOPO vector to generate the internal control plasmid “pCR-CLUS" . 


\section{RESULTS AND DISCUSSION}

Clusterin mRNA expression in apoptosis was first determined using isolated rat thymocytes. For this, freshly prepared single cell suspensions were incubated with the synthetic glucocorticoid dexamethasone (DEX) for different time values, and then

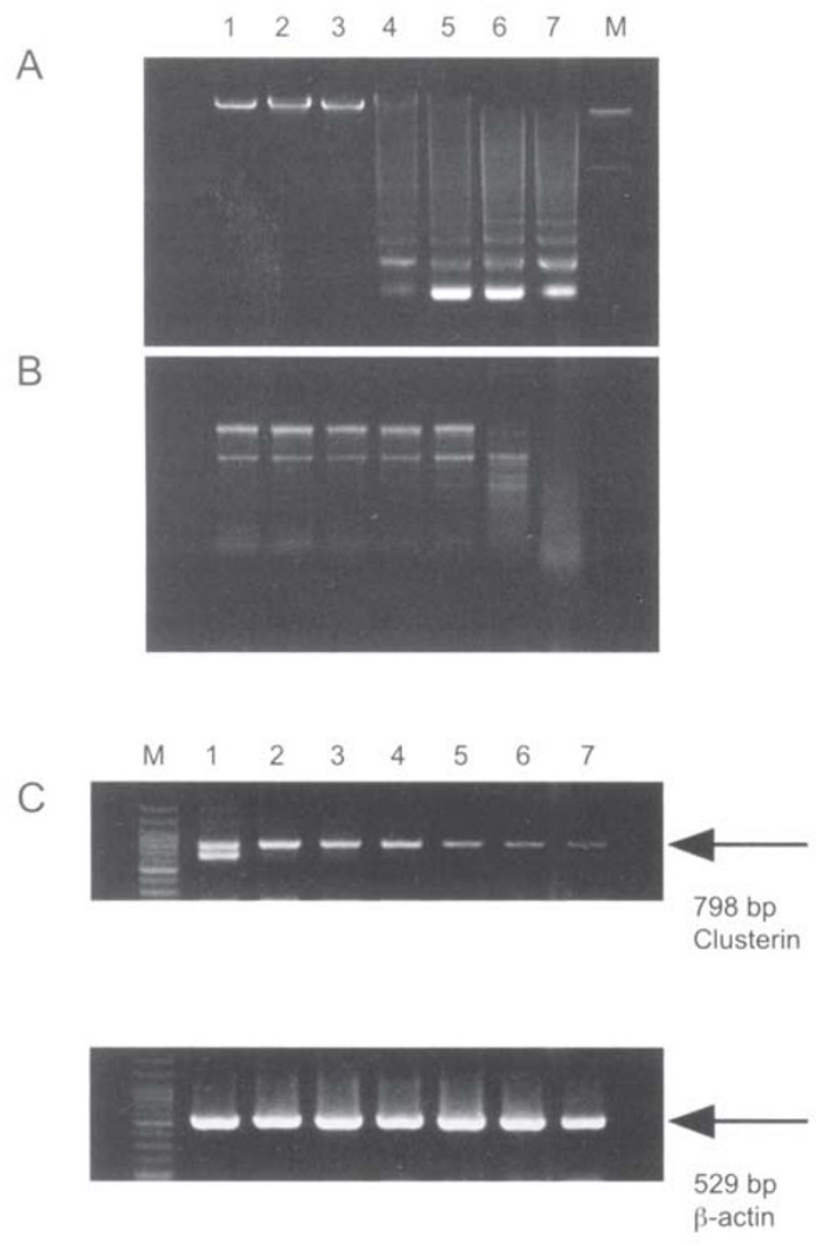

Fig 1. Clusterin mRNA expression in course of dexamethasone-induced apoptosis of rat thymocytes in vitro. Isolated rat thymocytes were treated with dexamethasone for differing time values to induce apoptosis. A. Analysis of genomic DNA shows inter-nucleosomal degradation in DEX-treated thymocytes. B. Total RNA analysis using a denaturing agarose gel shows that RNA degradation is accompanied with apoptosis. C. Clusterin and $\beta$-actin mRNA expression in apoptotic thymocytes. M, molecular weight marker (100 bp ladder); 1 , freshly isolated thymocytes; 2 , thymocytes treated with DEX for $30 \mathrm{~min}$; 3, thymocytes treated with DEX for 1 h; 4 , thymocytes treated with DEX for $4 \mathrm{~h} ; 5$, thymocytes treated with DEX for $8 \mathrm{~h} ; 6$, thymocytes treated with DEX for $24 \mathrm{~h}$; 7, thymocytes treated with DEX for $48 \mathrm{~h}$. clusterin mRNA expression was analyzed by RTPCR. Fig 1A confirms the successful induction of apoptosis by DEX-treatment in vitro. Fragmentation of genomic DNA into a 200-bp ladder was very weakly initiated after the first hour of DEX treatment and only after $4 \mathrm{~h}$, a definitive 200-bp ladder was visible. Interestingly, DNA degradation was also accompanied by a gradual loss of total RNA with increasing incubation time, which had a later onset time than the degradation of genomic DNA (Fig 1B). Most surprisingly, the relative level of clusterin mRNA expression was largely unaffected by inducing thymocyte apoptosis. Rather, it is evident that the clusterin signal intensity diminished during the progress of apoptosis (Fig 1C). Since the relative amounts of RNA between different time points were normalized by adjusting to the $\beta$-actin signal (Fig $1 \mathrm{C}$ ), the present results suggest that clusterin mRNA expression is clearly not up-regulated by induction of apoptosis in thymocytes. Based on this observation, we are ruling out that clusterin expression is directly affected by thymocyte apoptosis. Since most of the previously published studies had determined clusterin mRNA expressions only using RNA from whole thymic tissues and by DEX-administration in vivo[7,14,15,21], the results on the effect of apoptosis induction in isolated thymocyte single cell suspensions in vitro had been not available so far. Regarding the fact that immature thymocytes are the primary targets for inducing apoptosis in DEXtreatment, the current study precisely shows, without involving interfering background signals from thymic stromal cells, that clusterin mRNA expression is not induced in apoptotic cells. Therefore, these in vitro data rather supports the reports from Pearse et al[15] and French et al[14], who have described no apparent connection between apoptosis and clusterin mRNA level. In the present system, clusterin mRNA expression selectively decreases in course of DEX-induced apoptosis (Fig 1C), therefore it is evident that clusterin plays no substantial role in protecting or promoting apoptosis in thymocytes.

In the course of these experiments we isolated a clusterin RT-PCR product that was subsequently identified to be a novel isoform of rat clusterin mRNA. As shown in Fig 1C, a low molecular weight RT-PCR product was observed in freshly isolated 
thymocytes but not anymore after transferring cells into in vitro culture. To confirm that this low molecular weight band is indeed a novel isoform of clusterin mRNA and not a PCR artefact, the PCR products were cloned and their nucleotide sequence determined. Whereas the upper high-molecular PCR band exactly matched the published clusterin mRNA sequence from rat Sertoli cells, the low-molecular weight PCR band encoded a novel isoform of rat clusterin (Fig 2A). The nucleotide sequence of this PCR product has been deposited in GenBank (accession number AF314657), and Fig 2 shows the deduced amino acid sequence of the isoform compared to the published clusterin sequence. The schematic presentation of this new isoform (Fig 2B) in- dicated that the proteolytic cleavage site, which is responsible for generating the a- and b-subunits of the mature clusterin, is deleted. Based on this property, we predict that the novel isoform encodes a monomeric protein that is different from the native clusterin protein, which exists as a heterodimer [9]. The physiological function of such a protein, and the biological meaning of its expression being completely inhibited by transfer into in vitro culture, is not clear. But it is possible that some cellular signals that were present in vivo are lacking in media, and therefore the expression of this isoform can not be maintained. The identity of this signal or the conditions that result in the expression (or suppression) of this isoform are not known to us, so far.

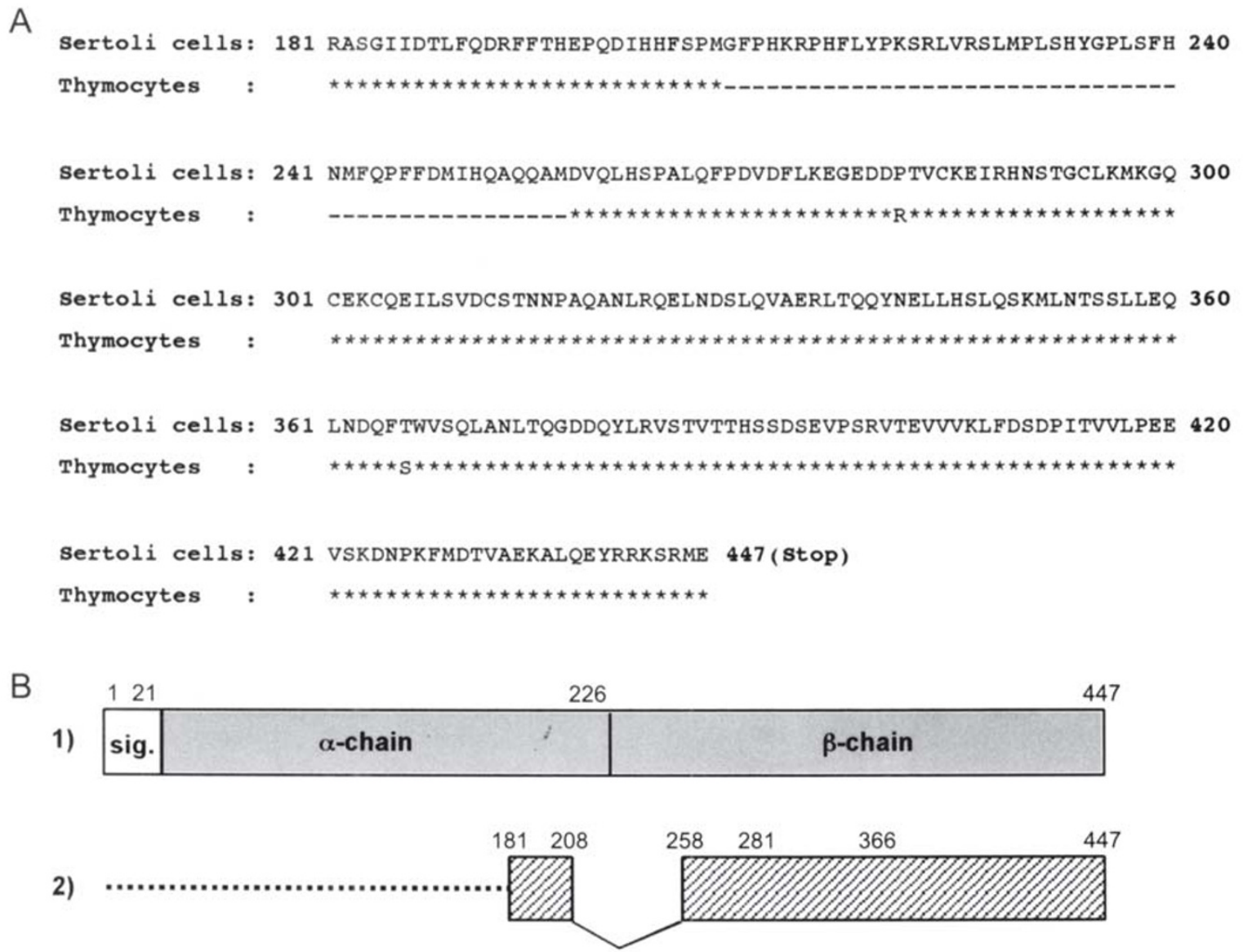

Fig 2. Molecular cloning and sequencing of a novel clusterin mRNA isoform, which expression is suppressed by induction of apoptosis A. The clusterin mRNA isoforms as seen in Fig 1C lane 1 were cloned and their nucleotide sequences were determined. The sequence of this novel deletion isoform was deposited into the GenBank (No. AF314657). B. Schematic presentation of the amino acid (a.a.) sequence between the published original clusterin [1] and the newly cloned isoform [2]. The a.a. 1-21 corresponds to the signal peptide sequence. Position 226 is the proteolytic cleavage site, which splices the translated product into the $\beta$ - and $\beta$-subunits. The dotted line to the 5 '-upstream region of the novel isoform represents the sequence of the isoform, which has still to be determined. 
Nevertheless, it is evident that neither driving cells to apoptosis (Fig 1) nor inducing activation (Fig 3) can restore this selective expression. Molecular cloning of the whole cDNA of this novel isoform and its recombinant expression in mammalian cells are expected to resolve the issue about its biological role and help clarify the issues regarding its specific expression in vivo.

Since clusterin mRNA level was not up-regulated in the course of apoptosis, we further questioned whether clusterin expression would be a regulatory event at all. Therefore, to examine if clusterin expression might be affected by other cellular signals, thymocytes were activated with concanavalin A (Con A) and interleukin-2 (IL-2), which are well known T-cell stimulatory agents[23]. Thymocytes were either maintained in culture media for 1, 2 or 3 days under normal culture conditions or activated with Con A and IL-2 for the same time span. Interestingly, in the latter case, a significant induction of clusterin mRNA expression was observed, which was in good contrast to thymocytes incubated in media without any activation signals (Fig 3). To extend this observation to protein expression levels, as well as to evaluate the correlation of transcrip-
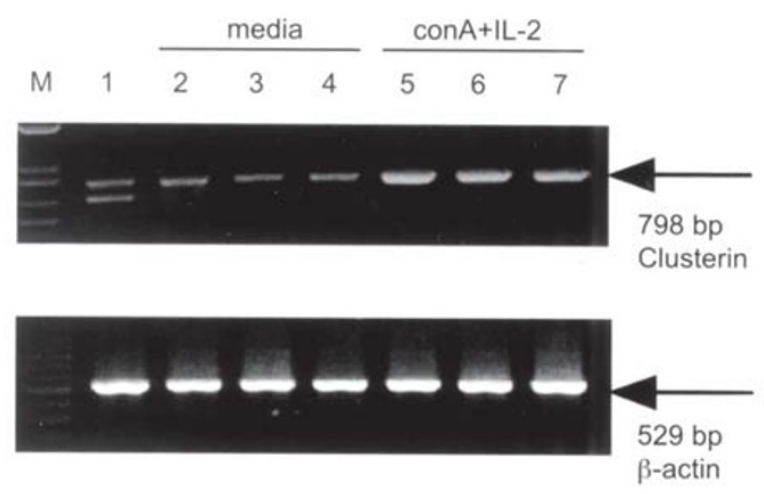

Fig 3. Induction of clusterin expression by stimulation with concanavalin A and interleukin-2 The effect of stimulatory signals on clusterin expression in rat thymocytes was examined by RT-PCR. Freshly isolated rat thymocytes were either treated with con A and IL-2 or left in media for 1, 2 and 3 days. M, molecular weight marker; 1 , freshly isolated thymocytes; 2 , thymocytes cultured in RPMI-1640 media for 1 day; 3, thymocytes cultured in RPMI-1640 media for 2 days; 4, thymocytes cultured in RPMI-1640 media for 3 days; 5 , thymocytes activated with con A and IL-2 for 1 day; 6 , thymocytes activated with con A and IL-2 for 2 days; 7, thymocytes activated with con A and IL-2 for 3 days. tional and translational activities in clusterin expression, immunoblot analysis was performed. Fig 4 shows the result of a representative Western blot, where freshlyisolated thymocytes were either cultured in media, induced to apoptosis with DEX or triggered to activation by Con A and IL-2 treatment. While apoptotic thymocytes (DEX-treatment) do not have increased levels of clusterin expression (lane 2 ), activation of thymocytes with lectin and IL-2 showed a significant increase (lane 3), which is in agreement with the data from mRNA analysis. We conclude from these results that, while untreated rat thymocytes do express clusterin per se, its expression level is not affected by apoptosis but is induced and up-regulated by cellular activation and proliferation signals.

To examine the regulatory mechanisms for clusterin expression under in vivo situations, young adult rats were intra-peritoneally injected with DEX or with vehicle, and clusterin mRNA expression in their thymi was determined. The in vivo adminis-

A
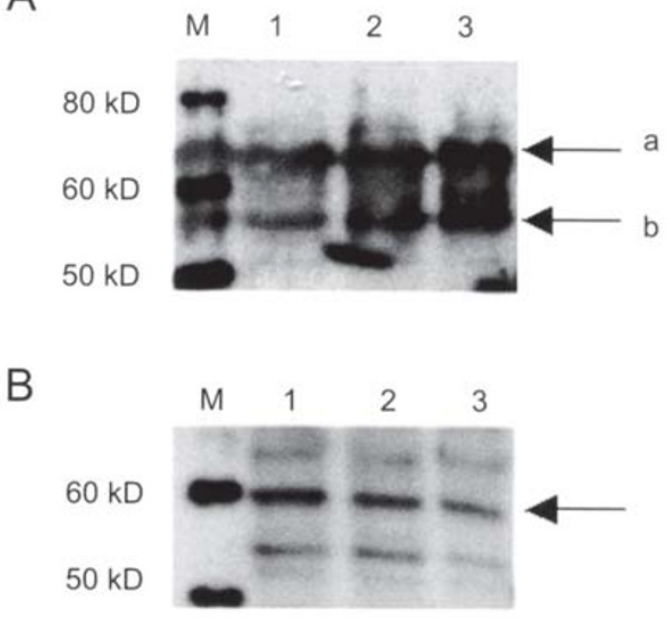

Fig 4. Western blot analysis of clusterin expression in apoptotic and activated cells. A. Cell lysates of rat thymocytes incubated in media for 6 hours (1.) or treated with DEX (2.) or activated with ConA and IL-2 (3.) for the same time frame were resolved in a $12 \%$ SDS- polyacrylamide gel and blotted onto a PVDF membrane. Clusterin expression was then detected with rabbit-anti rat clusterin polyclonal antibodies, and specific binding was visualized by enhanced chemiluminescence. Arrows indicate the clusterin signals (a. mature clusterin; b. putative clusterin b-chain). B. An aliquot of the same cell lysate was probed in a parallel Western blot with anti-actin antibodies to show that equal amount of proteins were used for analysis. Arrow indicate the position of actin. 
tration with DEX is known to induce massive apoptosis in mostly immature thymocytes, and this model has been frequently used for analysis of cellular events accompanying programmed cell death [24]. In our current study, the differences in clusterin expression were examined in a more quantitative manner for which a semi-quantitative RTPCR was designed[22], that is based on the primer competition to clusterin cDNA and an internal control vector. The construction of internal competitor molecules for rat clusterin and b-actin is shown in Fig
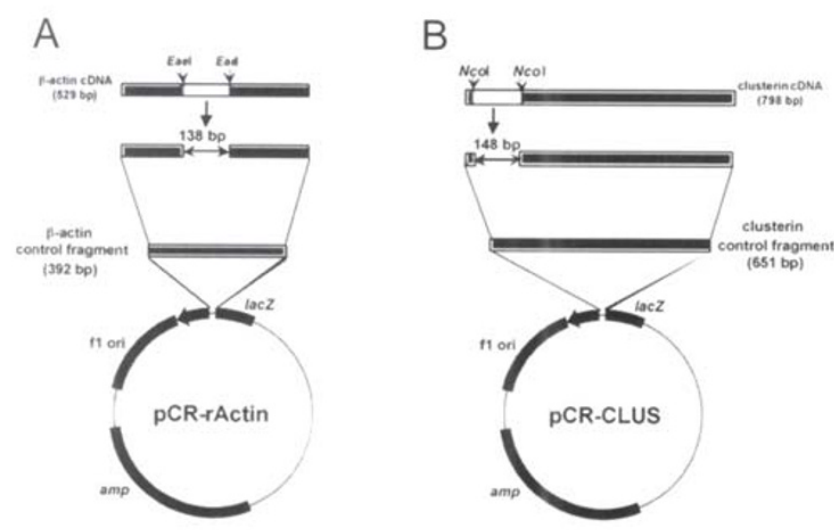

Fig 5. Construction of control vectors for semi-quantitative RT-PCR analysis of clusterin mRNA expression A. The $\beta$ actin control vector was generated to produce a primer competitor fragment when used in the co-amplification of rat thymocyte cDNA. After RT-PCR amplification of a b-actin cDNA fragment, the PCR product was treated with the restriction enzyme EaeI to excise a 138 bp segment. The enzyme reaction was then used as template for another round of PCR, whereby the shortened 392 bp product was subcloned into the pCR vector. B. The construction of the clusterin control vector was performed in the same manner as for the $\beta$-actin control vector, whereby the NcoI enzyme was used to excise a $149 \mathrm{bp}$ fragment from the original cDNA product.

5.

When using the pCR-CLUS vector, the oligonucleotide primers "Clusterin-up" and "Clusterindown” will generate a 798 bp PCR product, which is $148 \mathrm{bp}$ longer than the that generated using rat thymocyte cDNA as template. The size difference enables us to distinguish the template origin of the PCR product, and in this manner, the relative amounts of clusterin mRNA can be estimated and compared. Normalization of total RNA amount was achieved in a semi-quantitative RT-PCR using the $\beta$-actin internal control plasmid, pCR-rActin. The 100 bp difference between cDNA-derived and control plasmid originated PCR products enabled the discrimination of the DNA band. After quantification and normalization of $\beta$-actin mRNA level, clusterin expression was analyzed in normal and apoptotic rat thymi.

The successful induction of apoptosis in vivo in DEX-treated rats was visualized by measuring the size differences between the thymi. As shown in Fig $6 \mathrm{~A}$, a drastic shrinkage of the organ size is observed which indicates the loss of cellularity upon induction of apoptosis. Further confirmation of the apoptotic process was obtained by the phenotypic analysis of the isolated thymocytes. As shown in Fig $6 \mathrm{~B}$, in DEX-treated rats, the immature CD4+, CD8+ double positive cell population was reduced to about $65 \%$ of all thymocytes, compared to $85 \%$ in untreated rats. The clusterin level between apoptotic and normal thymocytes was then semi-quantitatively determined by competitive RT-PCR. This assay is based on the primer competition of co-amplified control vectors with reverse transcribed cDNA. By prior determination of the concentration of the competitor molecules, the amount of the mRNA in interest can be estimated. As shown in Fig $7, \beta$-actin signals were normalized between the two different probes, and then the clusterin mRNA levels were compared to each other. Using a serial dilution of competitor molecules, the relative amounts of clusterin mRNA were estimated to be equal or slightly less (2-fold) in DEX-treated rats compared to normal rats (Fig 7). In this regard, it is evident that induction of apoptosis, neither in vivo nor in vitro, up-regulates clusterin mRNA expression. Although other report show where clusterin is induced upon apoptosis in rat prostate cells [7] and renal tubular epithelium during tissue regression[3], our data suggest that clusterin expression would be not an universal indicator in apoptotic cells.

In conclusion, the present study shows that under both in vivo and in vitro conditions, induction of apoptosis in rat thymocytes is not associated with clusterin expression. In addition, neither a cell death protective nor an apoptosis-promoting role of clusterin could be assigned based upon the current observations. This is actually in contradiction to some previous results, where alterations in clusterin ex- 
pression were observed upon induction of apoptosis [11],[16]. A possible explanation for this discrepancy might be differences in the condition of delivering cell death-inducing signals, since it has been also previously reported that the quality of the cell death inducing signal can differently regulate and affect clusterin expression under apoptotic conditions[25]. In this regard, it could be speculated that DEX-induced apoptosis initiates a unique "Clusterinindependent" cell death program in thymocytes than apoptotic signals that are triggered, for example, in regressing rat ventral prostate, where clusterin expression has been repeatedly confirmed to be elevated[26]. On the other hand, we think it is rather more likely that the present results are in agreement with the view of Koch-Brandt and Morgans[27], which postulates that the up-regulation of clusterin expression in apoptotic tissues origins from intact bystander cells rather than the apoptotic cells themselves. Since, DEX-induced apoptosis is mostly confined to CD4, CD8 double positive thymocytes, in vivo treatment of DEX would not affect thymic stroma cells. Therefore, while immature thymocytes are induced to cell death, stroma cells would not receive any signals for apoptosis, which might explain the absence of clusterin induction in DEX-injected thymi.

Nevertheless, evidence that clusterin indeed plays a cytoprotective role has been recently re-confirmed with the generation of clusterin-deficient mice, in
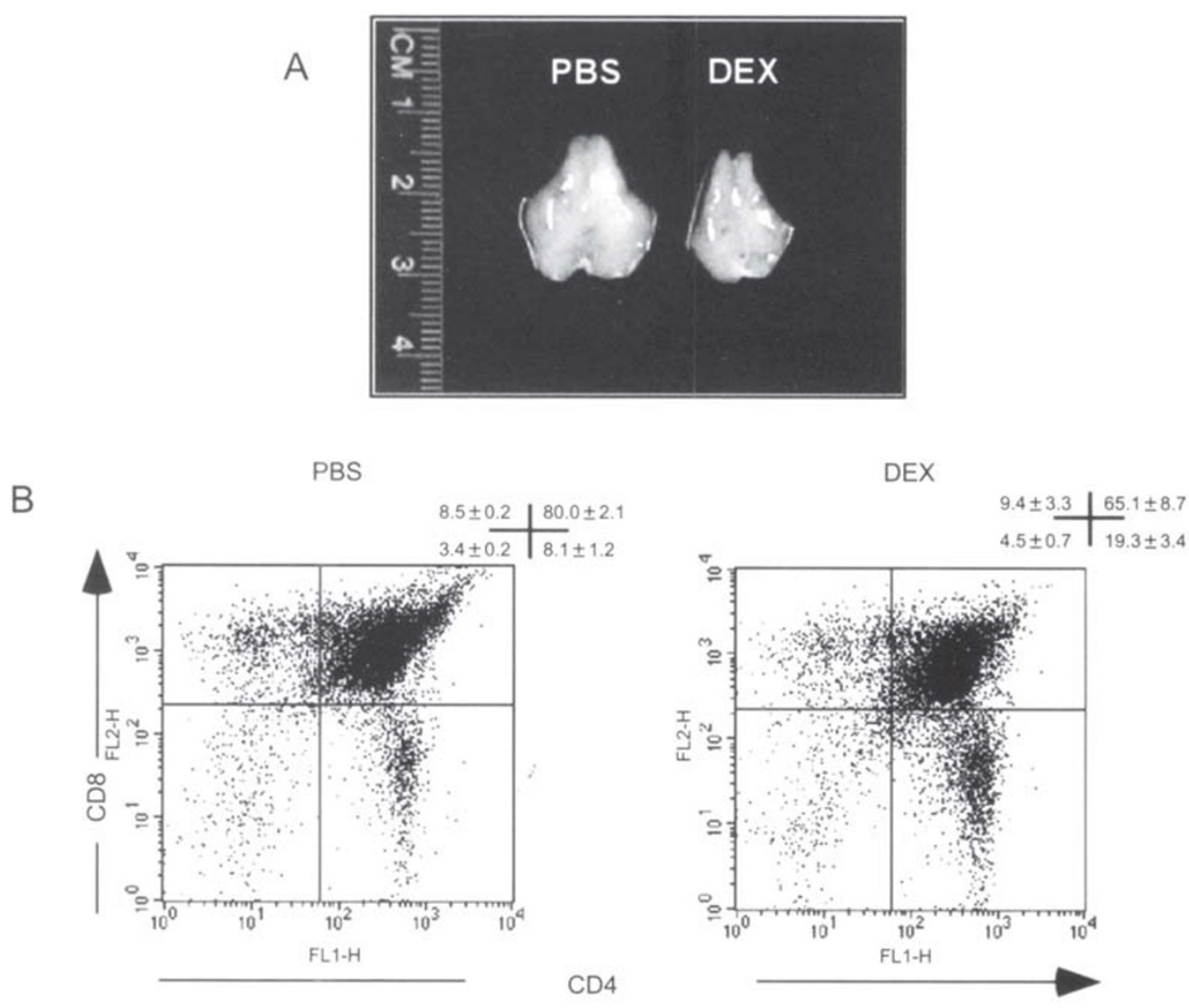

Fig 6. Induction of thymocyte apoptosis in vivo by peritoneal administration of dexamethasone A. Difference in thymus size by dexamethasone administration. The drastic reduction of cell numbers by apoptosis upon dexamethasone treatment is easily visualized by comparison of the thymus size between vector and dexamethasone-injected rats. B. Flow cytometric analysis. Difference in the CD4/ CD8 profile of rat thymocytes before and after dexamethasone-treatment. A representative result from 3 independent experiments is shown in the dot plot. The numbers in the quadrants show the mean +/- S.E. (standard error) from these experiments. 

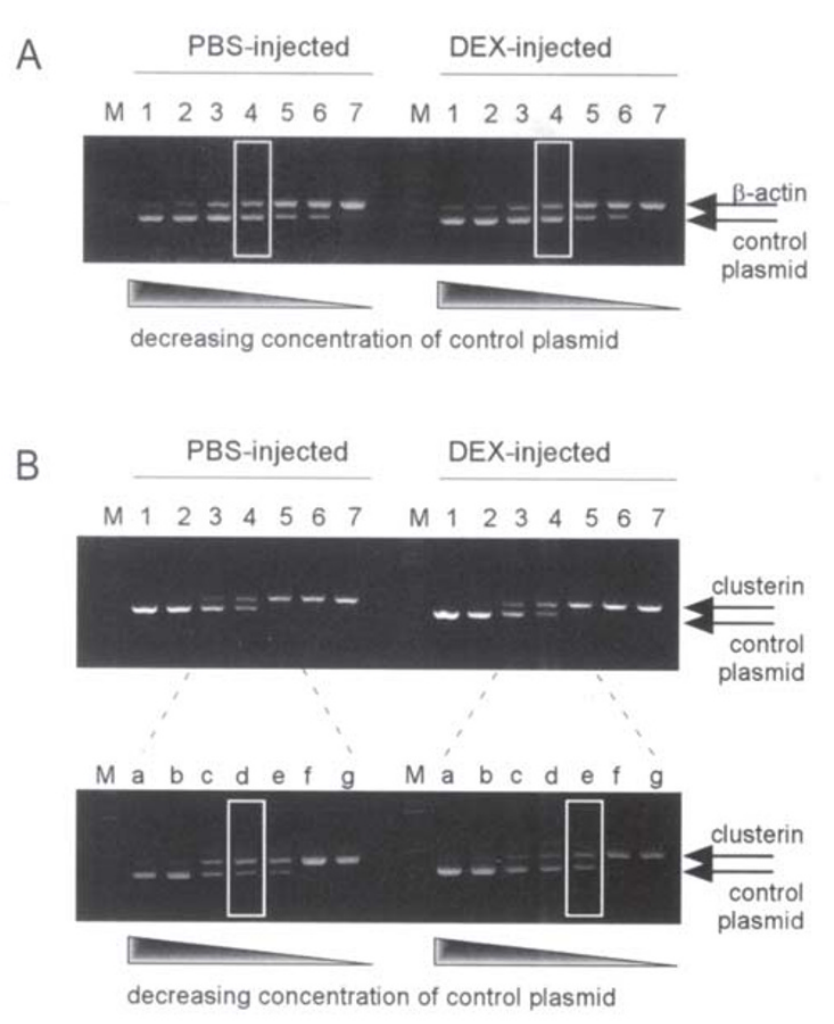

Fig 7. Semi-quantitative analysis of clusterin mRNA expression after induction of apoptosis in vivo. A. Competitive PCR of cytoplasmic $\beta$-actin mRNA signals from PBS- or DEXinjected rats. $\mathrm{M}$, molecular weight marker; $1,10^{11}$ copies of the $\beta$-actin control plasmid; $2,10^{10}$ copies; $3,10^{9}$ copies; $4,10^{8}$ copies; $5,10^{7}$ copies; $6,10^{6}$ copies; $7,10^{5}$ copies. White boxes indicate the equivalence points. B. Competitive PCR of clusterin mRNA signals from PBS- or DEX-injected rats. M, molecular weight marker; $1,10^{11}$ copies of the clusterin control plasmid; $2,10^{10}$ copies; $3,10^{9}$ copies; $4,10^{8}$ copies; $5,10^{7}$ copies; $6,10^{6}$ copies; $7,10^{5}$ copies. For a more precise determination of the copy numbers a further competitive PCR was performed. M, molecular weight marker; a, $10^{9}$ copies of the clusterin control plasmid; b, $5 \times 10^{8}$ copies; c, $10^{8}$ copies; d, $5 \times 10^{7}$ copies; e, $10^{7}$ copies; f, $5 \times 10^{6}$ copies; $7,10^{6}$ copies. White boxes indicate the equivalence points.

which it was shown that clusterin limited the progression of autoimmune myocarditis and prevented long-term myocardial damages[28]. Additionally, heat-shock-mediated apoptosis in prostate cells was accelerated in these animals, proving again the involvement of clusterin in programmed cell death[29]. In reference to such reports, as well as on previous observations on clusterin induction and accumulation in thymi, the present study has aimed to re- solve the issue regarding a putative pro- or antiapoptotic role of clusterin in rat thymocytes. Since developing immature thymocytes are susceptible to apoptosis during maturation[30], the thymus is an excellent organ to analzye such programmed cell death-associated phenomena. Based on our observations, we propose that apoptosis of thymocytes is not associated with an induction of clusterin expression. However, the role of constitutively expressed clusterin in thymic tissues and thymocytes remains still undetermined. Further studies, using clusterin-specific antibodies and the use of whole tissue section of apoptosis-induced organs will provide some clues on such questions.

\section{ACKNOWLEDGEMENTS}

This work was supported by grant No. R05-2001000-00464-0 from the Basic Research Program of the Korea Science and Engineering Foundation. The authors are very thankful to M.L. Cowan for corrections and suggestions to the text.

\section{REFERENCES}

[1] Blaschuk O, Burdzy K, Fritz IB. Purification and characterization of a cell-aggregating factor (clusterin), the major glycoprotein in ram rete testis fluid. J Biol Chem 1983; 258:7714-20.

[2] Fritz IB, Burdzy K, Setchell B, Blaschuk O. Ram rete testis fluid contains a protein (clusterin) which influences cell-cell interactions in vitro. Biol. Reprod. 1983; 28: 1173-88.

[3] Jenne DE, Tschopp J. Clusterin: the intriguing guises of a widely expressed glycoprotein. Trends Biochem Sci 1992; 17:154-9.

[4] Gelissen IC, Hochgrebe T, Wilson MR, Easterbrook-Smith SB, Jessup W, Dean RT, Brown AJ. Apolipoprotein J (clusterin) induces cholesterol export from macrophagefoam cells: a potential anti-atherogenic function? Biochem J 1998; 331:231-7.

[5] Kirszbaum L, Sharpe JA, Murphy B, d' Apice AJ, Classon B, Hudson P, Walker ID. Molecular cloning and characterization of the novel, human complement-associated protein, SP-40, 40: a link between the complement and reproductive systems. EMBO J 1989; 8:711-8.

[6] Humphreys DT, Carver JA, Easterbrook-Smith SB, Wilson MR. Clusterin has chaperone-like activity similar to that of small heat shock proteins. J Biol Chem 1999; 274 : 6875-81.

[7] Montpetit ML, Lawless KR, Tenniswood M. Androgenrepressed messages in the rat ventral prostate. Prostate 1986; 8:25-36.

[8] Lee KH, Ji YM, Lim HM, Lee SC, You KH. Molecular cloning and sequencing of sulfated glycoprotein-2 cDNA 
from testis of mouse: implications of two different mRNAs of 㥆GP-2. Biochem Biophys Res Commun 1993; 194: 1175-80.

[9] Wilson MR, Easterbrook-Smith SB. Clusterin is a secreted mammalian chaperone. Trends Biochem Sci 2000; 25: 95-8.

[10] Bettuzzi S, Hiipakka RA, Gilna P, Liao ST. Identification of an androgen-repressed mRNA in rat ventral prostate as coding for sulphated glycoprotein 2 by cDNA cloning and sequence analysis. Biochem J 1989; 257:293-6.

[11] Bettuzzi S, Troiano L, Davalli P, Tropea F, Ingletti MC, Grassilli E, Monti D, Corti A, Franceschi C. In vivo accumulation of sulfated glycoprotein 2 mRNA in rat thymocytes upon dexamethasone-induced cell death. Biochem Biophys Res Commun 1991; 175:810-5.

[12] Michel D, Moyse E, Trembleau A, Jourdan F, Brun G. Clusterin/ApoJ expression is associated with neuronal apoptosis in the olfactory mucosa of the adult mouse. J Cell Sci 1997; 110:1635-45.

[13] Klock G, Storch S, Rickert J, Gutacker C, Koch-Brandt C. Differential regulation of the clusterin gene by Ha-ras and c-myc oncogenes and during apoptosis. Cell Physiol 1998; 177:593-605.

[14] French LE, Sappino AP, Tschopp J, Schifferli JA. Clusterin gene expression in the rat thymus is not modulated by dexamethasone treatment. Immunology 1994; 82:328-31.

[15] Pearse MJ, O’ Bryan M, Fisicaro N, Rogers L, Murphy B, d' pice AJ. Differential expression of clusterin in inducible models of apoptosis. Intl Immunol 1992; 4:122531.

[16] French LE, Sappino AP, Tschopp J, Schifferli JA. Distinct sites of production and deposition of the putative cell death marker clusterin in the human thymus. J Clin Invest 1992; 90:1919-25.

[17] Viard I, Wehrli P, Jornot L, Bullani R, Vechietti JL, Schifferli JA, Tschopp J and French LE. Clusterin gene expression mediates resistance to apoptotic cell death induced by heat shock and oxidative stress. J Invest Dermatol 1999; 112:290-6.

[18] Yang CR, Leskov K, Hosley-Eberlein K, Criswell T, Pink JJ, Kinsella TJ, Boothman DA. Nuclear clusterin/XIP8, an X-ray-induced Ku70-binding protein that signals cell death. Proc Natl Acad Sci USA 2000; 97:5907-12.

[19] Sun X-M, Dinsdale D, Snowden RT, Cohen GM, Skilleter
DN. Characterization of apoptosis in thymocytes isolated from dexamethasone-treated rats. Biochem Pharmacol 1992; 44:2131-7.

[20] Park JH, Mitnacht R, Torres-Nagel N, Hunig T. T cell receptor ligation induces interleukin (IL) $2 \mathrm{R}$ beta chain expression in rat CD4, 8 double positive thymocytes, initiating an IL-2-dependent differentiation pathway of CD8 alpha+/beta- T cells. J Exp Med 1993; 177:541-6.

[21] Cohen JJ, Duke RC. Glucocorticoid activation of a calcium-dependent endonuclease in thymocytes nuclei leads to cell death. J Immunol 1984; 132:38-42.

[22] Dumoulin FL, Altfeld M, Rockstroh JK, Leifeld L, Sauerbruch T, Spengler U. Semiquantitation of human chemokine mRNA levels with a newly constructed multispecific competitor fragment. J Immunol Meth 1999; 224:61-7.

[23] Flach R, Cattaruzza M, Koch-Brandt C. Clusterin gene expression in apoptotic MDCK cells is dependent on the apoptosis-inducing stimulus. Biochim Biophys Acta 1995; 1268:325-8.

[24] Lakins J, Bennett SAL, Chen JH, Arnold JM, Morrissey C, Wong P, O’ Sullivan J, Teniswood M. Clusterin biogenesis is altered during apoptosis in the regressing rat ventral prostate. J Biol Chem 1998; 273:27887-95.

[25] Koch-Brandt C, Morgans C. Clusterin: a role in cell survival in the face of apoptosis? Prog Mol Subcell Biol 1996; 16:130-49.

[26] Chomczynski P, Sacchi N. Single-step method of RNA isolation by acid guanidium thiocyanate-phenol-chloroform extraction. Anal Biochem 1987; 162:156-9.

[27] Homburg CHE, De Haas M, von dem Borne AEGKr, Verhoeven AJ, Reutelingsperger CPM, Roos D. Human neutrophils lose surface Fcg RIII and acquire annexin V binding sites during apoptosis in vitro. Blood 1995; 85: 532-40.

[28] McLaughlin L, Zhu G, Mistry M, Ley-Ebert C, Stuart WD, Florio CJ, Groen PA, Witt SA, Kimball TR, Witte DP, Harmony JA, Aronow BJ. Apolipoprotein J/clusterin limits the severity of murine autoimmune myocarditis. J Clin Invest 2000; 106:1105-13.

[29] Bailey RW, Aronow B, Harmony JA, Griswold MD. Heat shock-initiated apoptosis is accelerated and removal of damaged cells is delayed in the testis of clusterin/ApoJ knock-out mice. Biol Reprod 2002, 66:1042-53.

[30] Hunig T, Torres-Nagel N, Mehling B, Park JH, Herrmann $\mathrm{T}$. Thymic development and repertoire selection: the rat perspective. Immunol Rev 2001; 184:7-19. 